\title{
Effect of Weight Training Exercises on the Improvement of Arm and Leg Strength of Wrestlers
}

\author{
Arif Mohammad, Ph.D. \\ Assistant Professor of Physical Education, Department of Teacher Training and Non Formal \\ Education (IASE), JamiaMilliaIslamia, New Delhi, INDIA. \\ amohammad3@jmi.ac.in
}

\begin{abstract}
The purpose of the study was to realize the effect of selected weight training exercises on the growth of arm and leg strength of wrestlers. To work on the purpose 20 wrestlers who were the students of SKR College of Physical Education, Kharar, Punjab were taken as the subjects. The selected group of subjects wasdivided into two groups viz. experimental and control. The weight training schedule which was administered on experimental group only, different weight training exercises were given (i.e. standing barbell curls, standing dumbell curls, dumbel hammer curls, incline dumbell curls, precher curls, dumbell concentration curls, lying barbell extension, close grip bench press, triceps dumbell extensions, triceps bench dips, squat, dumbell lunges, standing leg curls, dumbell dead lift, and leg press). This weight training programme were carried out for a period of 8 weeks for one hour every evening, excluding Tuesday, Thursday, Saturday, and Sunday. Control groups was no treatment group and were enaged in their own daily activity programme. As delimited to measure the leg strength of the subjects standing broad jump (SBJ) and to measure the arm strength pull-ups tests were used. For the administration and scoring of these tests item procedure mentioned in AAPHER, youth fitness test (1958) was taken as the model. It was realize from the results of the study that there was significant effect of the weight training exercise on the leg strength as well as arm strength of the selected wrestlers.
\end{abstract}

Keywords: Wrestlers, arm strength, leg strength.

\section{INTRODUCTION}

Training is mainly an art and like the artist a successful training programme must have two attribute. The first one is creative training, which indicates success in any sports hinges on its ability to respond quickly of flexibly, strength, speed and reliably to player demands and better opportunities. The second attribute is technical mastery of the skills used (Shaker, 2007). Therefore, a systematic and appropriate training programme is a great asset for all players.

In the weight training resistance equipment is used to stimulate muscle growth, increase tone and strength. The term weight training is also used interchangeably as resistance training.It could be treated as strength training for developing the arm strength of wrestlers, butweight training should not be confused with weight lilting, which is the lifting of heavy weights with the goal of lifting more pounds than the opponent can (Shaw, \& Shaw, 2014). The confusion between weight lifting and weight training is probably the reason for the negative feelings about the use of weights in a boys training programme, since weight lifting is usually associated with powerful, muscled men, and has a masculine connotation. Silverter (2000) compared the effect of various resistance and free hand weight training exercise on leg strength, of seventy-nine male students. He calculated that all the training systems cause strength gains in all strength measures. Response to five different weight training frequencies per week 75 male volunteers' high school subjects were randomly assigned to train either one day, two days, four days per week. All groups trained on an identical bench press for nine weeks. The results revealed a highly significant improvement in muscular strength in the group that trained five days per week, sequential strength improvement resulted from increased frequencies of training that means the more frequent the stress, great adaptation will be happen. However, one can use weight training to improve an individual's general fitness and to raise level of performance in particular sports while at the same time adding to his femininity by improving his fatigue and muscle tone, since his muscles are strengthened by carefully selected weight training exercise (Shaker, 2007). It is well known that the services in the field of physical education have improved adequately in the past, but the only factor which perhaps does not seem to have been given adequate attention in the 
sports training. It is also established beyond doubt that the serious study in this area was never taken in order to spot out the gaps and subsequently bridge them. The scholar in the form of present study is making modest effort in this direction. Thus, the purpose of the study was to find the effect of selected weight training exercise on the development of arm and leg strength of wrestlers.

\section{Methods AND Materials}

\subsection{Subjects}

A total of 20 wrestlers who were the students of S.K.R. College of Physical Education, BhagooMajra, Kharar, were taken as the subjects of the study. According to the demand of the study total subjects were divided into two different groups A and B. A was experimental group comprising 10 wrestlers and were engaged in prescribed weight training schedule, whereas group B was control group comprising 10 wrestlers, were engaged in their own daily activity programme.

\subsection{Tools and Facility}

As delimited to measure the leg strength of the subjects standing broad jump (SBJ), and to measure the arm strength pull-ups tests were used. For the administration and scoring of these tests, procedure mentioned in AAPHER youth fitness test (1972) was taken as the model.

\subsection{Weight Training Schedule}

The pre design weight training programme was carried out for a period of 8 weeks for one hour every evening. In this the time required for conducting pre-test and post-test is excluded. The subjects underwent the weight training programme for thrice in the week that is, on Monday, Wednesday and Friday. Control group was treated as no treatment and was not subjected to any experimental training. The control group was allowed to engage themselves in their daily routine physical activities.

\subsection{Statistical Technique}

To find out theeffects of weight training exercise on legs and arm strength of wrestlers' student t-test was used between the pre-test and post-test data. The level of significance was set at 0.05 level. All statistical function was performance with the help of SPSS v.23 software.

\section{ReSUlts}

In the table given below results of the study is presented.

Table1. Mean, SD and T Value between Pre-Test and Post-Test Score of the Leg Strength for the both Control and Experimental Groups

\begin{tabular}{|l|l|l|l|l|}
\hline Group & N & Mean & SD & \multirow{2}{*}{ t value } \\
\cline { 1 - 4 } Experimental (Pre-test) & 20 & 1.77 & 0.22 & \multirow{2}{*}{$4.26^{*}$} \\
\cline { 1 - 4 } Experimental (Post-test) & 20 & 2.23 & 0.32 & \multirow{2}{*}{0.15} \\
\cline { 1 - 3 } Control (Pre-test) & 20 & 1.80 & 0.24 & \\
\cline { 1 - 3 } Control (Post-test) & 20 & 1.85 & 0.21 & \\
\hline
\end{tabular}

*Significant Tab $t_{0.05(18)}=2.10$

Readings of Table 1 showed that there is significant difference existed between pre-test and post-test score of leg strength of experimental group. For control group it was observed from the table that no significant difference existed between pre-test and post-test score of leg strength. It indicates that there is a significant effect of the weight training exercise on the leg strength of the wrestlers.

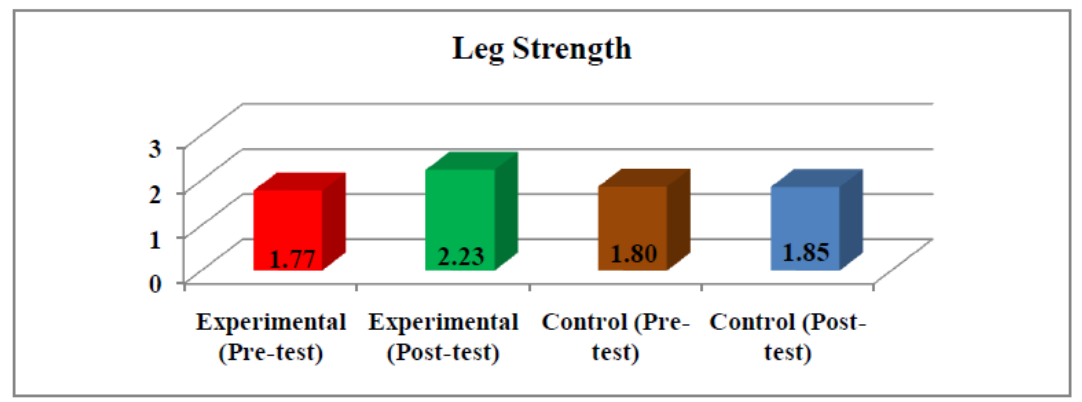

Figure1. Showing mean values of leg strength between pre and post test score of experimental and control groups 
Effect of Weight Training Exercises on the Improvement of Arm and Leg Strength of Wrestlers

Table2. Mean, SD and T Value between Pre-Test and Post-Test Score of Arm Strength for both Control and Experimental Groups

\begin{tabular}{|l|l|l|l|l|}
\hline Group & N & Mean & SD & \multirow{2}{*}{ t value } \\
\cline { 1 - 4 } Experimental (Pre-test) & 20 & 8.3 & 2.23 & \multirow{2}{*}{$4.82 *$} \\
\cline { 1 - 3 } Experimental (Post-test) & 20 & 11.1 & 2.09 & \multirow{2}{*}{1.59} \\
\hline Control (Pre-test) & 20 & 8.3 & 1.70 & \\
\hline Control (Post-test) & 20 & 8.7 & 1.61 & \\
\hline
\end{tabular}

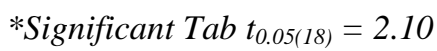

Readings of Table 2 showed that there is significant difference existed between pre-test and post-test score of arm strength of experimental group. For control group it was documented from the table that no significant difference existed between pre-test and post-test score of leg strength. It indicates that there is a significant effect of the weight training exercise on the arm strength of the wrestlers.

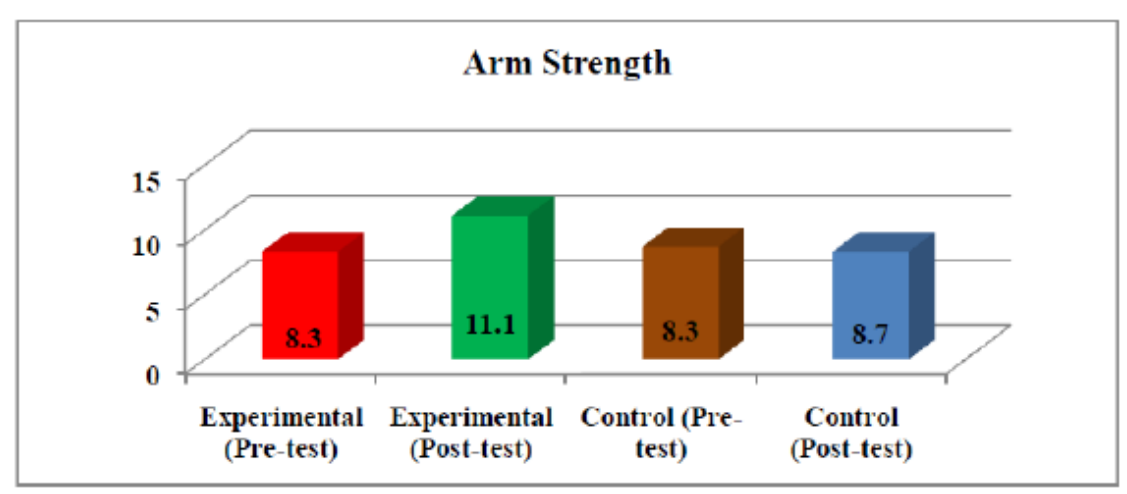

Figure2. Showing Mean Values of Arm Strength between Pre and Post Test Score of Experimental and Control Groups

\section{DisCuSSION}

The main purpose of the study was to examine the effect of selected weight training exercises on the development of strength ability of wrestlers. The secondary objective of the study was to know the effect of the selected weight training exercises on the arm and leg strength of wrestlers.

Table 1 showed the analysis of leg strength of pre-test and post-test scores of experimental and control groups. The mean values of experimental group was 1.77 (SD 0.22) for the pre-test, and 2.23 (SD 0.32) post-test respectively. The results of the $t$ test showed that difference existed between pre and post test score for experimental group. For control group it was found insignificant, which indicating that there is significant effect of eight weeks weight training exercise for leg strength improvement.

Results presented in Table 2 showed the analysis of arm strength of pre-test and post-test scores of experimental and control groups. The mean values of experimental group was 8.30 (SD 2.23) for the pre-test, and 11.10 (SD 2.09) post-test respectively. The results of the t test showed that difference existed between pre and post test score for experimental group. For control group it was found insignificant, which indicating that there is significant effect of eight weeks weight training exercise for arm strength improvement.

The findings of the present study indicate significant differences on arm and leg strength of experimental with comparison to control group. Control group findings indicate that there is no significant change in the arm and leg strength of wrestlers.

\section{Conclusions}

On the basis of the findings of the study following conclusions were made:

- Significant difference was observed between exprimental group and no significant between control groups on the variable arm and leg strength.

- It is found that prescribed weight training was effective on the arm and leg strengh of the wrestlerss. Treatment of weight training exercises increase in arm and leg strength.

- Finally, it is concluded that there is significant effect of the 8weeks weight training exercise programme on leg strength as well as arm strength of the wrestlers. 


\section{REFERENCES}

Arazi, H., \&Asadi, A. (2011). Effects of 8 weeks equal-volume resistance training with different workout frequency on maximal strength, endurance and body composition. International Journal of Sports Science and Engineering, 5(2), 112-118.

Cindy, A.D., Wayne, E.D., \& Loud, R.L. (1999). The effect of different resistance training protocols on muscular strength and endurance development in children. Official Journal of Pediatrics, 104(5), 147-152.

Darden, A. (2004). The new high intensity training. New Delhi, India: Friends Publication.

Elliott, K.J., Sale, C, \& Cable, N.T. (2002). Effects of resistance training and detraining on muscle strength and blood lipid profiles in postmenopausal women.British Journal of Sports Medicine, 36(5), 340-344.

Frank, W. (2006). Sports training principle. New Delhi, India: Friends Publication.

Harris, K.A., \& Holly, R.G. (1987). Physiological response to circuit weight training in borderline hypertensive subjects. Journal of Medical Science and Sports Exercise, 19(3), 246-252.

Izquierdo, M., Ibañez, J., González-Badillo, J.J., Häkkinen, K., Ratamess, N.A., Kraemer, W.J., ......, \&Gorostiaga, E.M. (2006). Differential effects of strength training leading to failure versus not to failure on hormonal responses, strength, and muscle power gains. Journal of Applied Physiology, 100(5), 1647-1656.

Madsen, K.L., Adams W.C. \& Van, M.D. (1998). Effects of physical activity, body weight and composition, and muscular strength on bone density in young women. Medical Science and Sports Exercise, 30(1),114-120.

McCartney, N., McKelvie, R.S., Martin, J., Sale, D.G., \& MacDougall, J.D. (1993). Weight-traininginduced attenuation of the circulatory response of older males to weight lifting. Journal of Applied Physiology, 74(3),1056-1060.

McCartney, N., Moroz, D., Garner, S.H., \&McComas, A.J. (1988). The effects of strength training in patients with selected neuromuscular disorders. Medical Science and Sports Exercise, 20(4), 362-368.

Munn, J., Herbert, R.D., Hancock, M.J., \&Gandevia, S.C. (2005). Training with unilateral resistance exercise increases contralateral strength. Journal of Applied Physiology, 99(5), 1880-1884.

Pal, I.S., (2009). The comparative effects of training, concentric training, eccentric training and their combination on strength of selected body segments. Journals of Sports Physiology, 2(2), 52-58.

Shaker, K.C. (2007). Sports training. New Delhi, India: Khel Sahitya Kendra.

Silverter, J. (2000). The effect of the variable resistance and free weight training program on leg strength, vertical jump and thigh circumference. Official Journal of Pediatrics, 18(10), 25-32.

Shaw, I..\& Shaw, B.S. (2014). Resistance training and the prevention of sports injuries. In: G. Hopkins, (ed.). Sports Injuries: Prevention, Management and Risk Factors. Nova Science Publishers, Hauppauge, NY. USA. 